\title{
DETERMINAÇÃO DO ESTOQUE DE CARBONO EM TECA (Tectona grandis L. F.) EM DIFERENTES IDADES
}

\author{
CARBON STOCK DETERMINATION IN TEAK (Tectona grandis L. F.) AT DIFFERENT AGES
}

\author{
Eleusa Maria Almeida ${ }^{1}$ José Holanda Campelo Júnior ${ }^{2}$ Zenesio Finger ${ }^{3}$
}

\section{RESUMO}

O objetivo deste trabalho foi avaliar a quantidade de carbono em cultivo de Teca (Tectona grandis L.f.), com 0,$5 ; 1,5 ; 2,5 ; 3,5$ e 5,5 anos de idade ao longo de um ano pertencentes à empresa BrasTeca Agroflorestal Ltda, localizada no município de Santo Antônio do Leverger, MT. O estoque de carbono em cada idade foi obtido a cada 90 dias, por meio da determinação da quantidade de massa seca da serapilheira acumulada, do teor de carbono orgânico no perfil do solo, da densidade de raízes no solo e da mensuração do volume do fuste e da copa em três plantas escolhidas ao acaso. A avaliação do tamanho das plantas, em altura total, diâmetro à altura do peito e projeção da copa, foi realizada em vinte plantas preservadas em cada idade. A quantificação do carbono da parte aérea foi realizada por meio do corte de três plantas em cada idade, obtendo a massa fresca total por componente. Para determinar a massa seca de raízes, utilizou-se a relação entre volume de solo e densidade de raiz de três plantas por idade, sendo realizadas quatro perfurações por planta, com seis subamostras cada, até a profundidade de $0,90 \mathrm{~m}$. O teor de carbono no solo e na serapilheira acumulada, a cada coleta e por idade, foi obtido após análise em laboratório. A quantidade média de carbono encontrada por hectare foi de 122,5 $\mathrm{t}$ de $\mathrm{C}$ para 0,5 ano, de 104,3 $\mathrm{t}$ de $\mathrm{C}$ para 1,5 ano, de 180,8 $\mathrm{t}$ de $\mathrm{C}$ para 2,5 anos, de 303,1 $\mathrm{t}$ de $\mathrm{C}$ para 3,5 anos e de 322,3 t de $\mathrm{C}$ para 5,5 anos, considerando o número de plantas por hectare nas diferentes idades. Verificou-se que a distribuição média de carbono por componente no sistema foi de $90,8 \%$ no solo, $5,04 \%$ para a parte aérea, $3,04 \%$ nas raízes e de $1,21 \%$ na serapilheira acumulada.

Palavras-chave: quantificação de carbono; plantação de Teca; massa seca.

\begin{abstract}
The objective of this study was to evaluate the quantity of carbon in teak (Tectona grandis L.f.), with $0.5 ; 1.5 ; 2.5 ; 3.5$ and 5.5 years of age, during one year. The teak evaluated belonged to the BRASTECA AGROFLORESTAL LTDA company, located in the municipality of Santo Antônio of Leverger, Mato Grosso, Brazil. The carbon stock for each age was assessed every 90 days by determining the amount of litter dry mass, organic carbon proportion in the soil, root density in the soil and the volume of the staff and crown in the three teak trees randomly selected for harvest. The assessment of the plant size, as height, diameter at chest height and crown projection, was carried out with twenty preserved plants at each age. The dry mass of the roots was determined from the relation between the soil volume and the density of roots of the three plants per age, by making four perforations per plant, with six samples for each, up to $0.90 \mathrm{~m}$ of depth. The carbon proportion in the soil and in the litter was obtained by age at each collection through laboratory analysis. The average carbon found per hectare was $122.5 \mathrm{t}$ of $\mathrm{C}$ at 0.5 years; $104.3 \mathrm{t}$ of $\mathrm{C}$ at 1.5 years; $180.8 \mathrm{t}$ of $\mathrm{C}$ at 2.5 years; $303.1 \mathrm{t}$ of $\mathrm{C}$ at 3.5 years and $322.3 \mathrm{t}$ of $\mathrm{C}$ at 5.5 years, considering the numbers of plants per hectare at the different ages. Afterward, the average distribution of carbon per system component was found to be $90.8 \%$ in the soil, $5.04 \%$ to the aerial part, $3.04 \%$ in the roots and $1.21 \%$ in the litter.
\end{abstract}

Keywords: carbon quantification; plantation of teak; dry mass.

1. Geógrafa, MSc., Professora do Instituto Federal de Educação Ciência e Tecnologia, Campus Bela Vista, CEP 78050-560, Cuiabá (MT). chaveal@terra.com.br

2. Engenheiro Agrônomo, Dr., Professor Titular do Departamento de Solos, Faculdade de Agronomia e Medicina Veterinária, Universidade Federal de Mato Grosso, Av. Fernando Corrêa da Costa, s/n, CEP 78060-900, Cuiabá (MT). jcampelo@terra.com.br

3. Engenheiro Florestal, Dr., Professor Associado do Departamento de Engenharia Florestal, Faculdade de Engenharia Florestal, Universidade Federal de Mato Grosso, Av. Fernando Corrêa da Costa, s/n, CEP 78060-900, Cuiabá (MT). fingerz@terra.com.br

Recebido para publicação em 17/01/2006 e aceito em 7/06/2010 


\section{INTRODUÇÃO}

É crescente a preocupação mundial com o aumento da concentração de gases na atmosfera, especialmente aqueles que têm a capacidade de reter parcialmente a radiação que é emitida pela terra. Entre esses gases, figura o dióxido de carbono $\left(\mathrm{CO}_{2}\right)$ que, desde a revolução industrial, teve sua concentração aumentada em aproximadamente $35 \%$. Esse aumento tem sido apontado como a principal causa de um eventual aquecimento da terra (aumento do efeito estufa), o qual poderá provocar mudanças climáticas potencialmente desastrosas nas próximas décadas, alterando a qualidade de vida no planeta. Assim sendo, devem ser estudadas e empregadas estratégias para redução da concentração do $\mathrm{CO}_{2}$ atmosférico.

As duas principais alternativas discutidas para enfrentar o problema ambiental são: o controle das emissões de gases, que tem forte resistência por parte dos países emissores, e a adoção de medidas compensatórias, aumentando o estoque de carbono na biomassa. Estas últimas compreendem, por exemplo, a preservação de florestas nativas, reflorestamento e plantio de árvores, que são responsáveis pela retirada de grande quantidade de $\mathrm{CO}_{2}$ da atmosfera, pelo processo de fotossíntese. O solo também pode ser uma importante opção de dreno do carbono da atmosfera e armazenamento temporário na forma de matéria orgânica.

$\mathrm{O}$ estoque de carbono pode ser quantificado por meio da estimativa da biomassa da planta acima e abaixo do solo e dos teores de carbono de cada componente, pela quantidade de carbono na serapilheira acumulada e no solo. Para se proceder à avaliação dos teores de carbono dos diferentes componentes do sistema é necessário, inicialmente, quantificar a biomassa de cada componente. Surge, com isso, a necessidade de conhecimento da vegetação no País, em relação à capacidade de capturar e estocar carbono.

A Teca (Tectona grandis L. f.) vem sendo empregada em reflorestamentos homogêneos, em todo o mundo, há mais de 100 anos com ótimos resultados. Ela é uma espécie natural das florestas tropicais (monsônicas) do sudeste e sudoeste asiático, conforme afirmam Finger et al. (2001), sendo esta reconhecida em todo mundo como madeira tropical dura e de alta qualidade, com preços estáveis e ascendentes no mercado nacional e internacional com franca expansão em áreas cultivadas (Oliveira, 2004).
Porém, o potencial de retenção de carbono é diferenciado para cada espécie e varia conforme o estádio de vida da planta. Sendo assim, o objetivo deste trabalho foi determinar o estoque de carbono em plantios de Teca, em diferentes talhões de cultivo que se apresentavam em diferentes estádios de crescimento (diferentes idades), ao longo do ano, com avaliações de três em três meses.

\section{MATERIAL E MÉTODOS}

O trabalho foi desenvolvido em uma área da Empresa BrasTeca Agroforestal Ltda, localizada no município de Santo Antônio do Leverger, MT, com latitude de $15^{\circ} 56^{\prime} 58^{\prime \prime} \mathrm{S}$ e longitude de $55^{\circ} 39^{\prime} 52^{\prime \prime} \mathrm{W}$; no período de 12.09.2003 a 11.09.2004. A região apresenta clima do tipo Aw, segundo Köppen, vegetação tipo cerrado e solos, de acordo com o Sistema Brasileiro de Classificação de Solos (EMBRAPA, 1999), nas partes mais baixas do terreno, sendo classificados como Argissolos Vermelho Amarelo Eutrófico Típico e Distrófico Típico.

As observações foram realizadas em cinco talhões de cultivo comercial de Teca cujas idades ou estádios de desenvolvimento e de áreas foram respectivamente 0,5 anos e 10 ha; 1,5 anos e 15 ha; 2,5 anos e 15 ha; 3,5 anos e 30 ha; 5,5 anos e 20 ha. O espaçamento utilizado no plantio foi de $2,2 \mathrm{~m} \mathrm{x}$ 3,0 m em todos os talhões.

As avaliações de biometria das plantas, por meio do diâmetro a altura do peito (DAP), altura total das plantas, projeção de copa (largura da copa na linha e na entrelinha) e altura da copa, foram realizadas de três em três meses, em uma parcela de vinte plantas, representativa de cada estádio (idade), preservada até o final do experimento.

Durante o ano de observação, o estoque de carbono em cada estádio ou idade foi determinado em função da fitomassa presente no respectivo talhão. A fitomassa da parte aérea foi obtida com a determinação do volume do fuste e do volume da copa das plantas e com as relações entre fitomassa do fuste e volume do fuste (densidade básica), e de massa foliar e volume da copa (densidade foliar), que foram determinados ao longo do trabalho, conforme descrito a seguir. Também foi determinada a quantidade de massa seca de serapilheira acumulada, o teor de carbono orgânico no perfil do solo e a quantidade de raízes no solo.

Para determinar o carbono na planta acima da superfície do solo, a cada 90 dias e em 
cada estádio (idade), foram cortadas três plantas previamente escolhidas e retiradas amostras de discos do tronco e amostras de massa verde de galhos e folhas para obter as relações entre o teor de carbono e as medidas de biometria das vinte plantas preservadas.

Antes das plantas serem cortadas, foram realizadas medidas de diâmetro do fuste com casca a $1,30 \mathrm{~m}$ (DAP), altura total $(\mathrm{Ht}) \mathrm{e}$ altura e projeção da copa. Após essas medições, o tronco foi seccionado para extração de discos de madeira com casca de aproximadamente $0,05 \mathrm{~m}$ de espessura, a $0,10 \mathrm{~m}$ e $1,30 \mathrm{~m}$ do solo e os demais discos foram extraídos de $1,0 \mathrm{~m}$ em $1,0 \mathrm{~m}$ até a altura total. $\mathrm{O}$ volume do fuste das plantas amostras com casca foi determinado pela aplicação da expressão de Smalian.

Os discos foram medidos, pesados e levados à estufa de circulação forçada de ar a $70^{\circ} \mathrm{C}$ para determinação da massa seca após peso constante. Serviram como amostras de madeira para o cálculo da densidade básica da madeira do fuste e do disco (DBMt) (Vital, 1984), com base na seguinte expressão:

$$
\overline{D B}=\frac{\sum_{N-1}^{i-1} V s i \times D B i}{\sum_{N-1}^{i-1} V s i}
$$

Em que:

$\overline{D B}=$ densidade básica, $\mathrm{g} \mathrm{cm}^{-3 ;}$

$V s i=$ volume de cada torete entre os discos (fórmula de Smalian), $\mathrm{m}^{3 ;}$

$D B i=$ densidade média de cada disco, $\mathrm{g} \mathrm{cm}^{-3}$.

$D B i=\frac{M}{V}$

$M=$ massa seca de cada disco, em g;

$V=$ volume verde de cada disco, $\mathrm{em}^{3}$.

Para a estimativa do volume de fuste das plantas preservadas foi utilizada a seguinte fórmula:

$V=\frac{\pi \times D A P^{2} \times H \times f f}{4}$

Em que:

$\pi=3,1416$

$D A P=$ diâmetro a altura do peito $(1,30 \mathrm{~m})$;

$H=$ altura total do fuste;

$f f=$ fator de forma.
As plantas amostradas foram desfolhadas e desgalhadas, e todo o material foi pesado. Do conjunto de folhas destacadas, retirou-se uma amostra de aproximadamente $500 \mathrm{~g}$. Do conjunto de galhos, foram retirados pedaços de galhos localizados em diferentes posições da copa da planta, os quais foram misturados, formando-se uma amostra composta, e retirada uma subamostra também de aproximadamente $500 \mathrm{~g}$. Para determinação da massa seca, ambos os tipos de subamostra foram levados à estufa de circulação forçada de ar a $70^{\circ} \mathrm{C}$ até atingirem peso constante.

A fitomassa do fuste das plantas-amostras foi obtida com as estimativas de volumes obtidas no campo, e com as estimativas de densidade básica obtidas em laboratório de acordo com a expressão (Herrera, 1989):

$$
P S(c)=V \times D B M t
$$

Em que:

$\mathrm{kg}$;

$P S(c)=$ peso seco do conjunto de fuste, $\mathrm{em}$

$V=$ volume do fuste, com casca, $\mathrm{em} \mathrm{m}^{3}$;

$D B M t=$ densidade básica média da madeira do fuste, $\mathrm{kg} \mathrm{m}^{-3}$.

No presente trabalho, a fitomassa de galhos e de folhas de cada planta amostra foi obtida pela expressão abaixo:

$$
P S(c)=\frac{P U(c) \times P S(a)}{P U(a)}
$$

Em que:

$P S(c)=$ peso seco do conjunto de galhos ou de folhas, em kg;

$P U(c)=$ peso úmido do conjunto de galhos ou de folhas no campo, em kg;

$P S(a)=$ peso seco da amostra de galhos ou de folhas, em kg;

$P U(a)=$ peso úmido da amostra de galhos ou de folhas, em $\mathrm{kg}$.

A determinação da fitomassa seca em cada estádio (idade) não se baseou exclusivamente na pesagem do total de material avaliado, mas nas relações massa-volume. Estas não foram realizadas em parcelas experimentais demarcadas especificamente para tal fim, mas de talhões de cultivo comercial. Dessa forma, a quantidade de carbono presente na fitomassa aérea foi estimada multiplicando as respectivas estimativas de 
biomassa pelo fator 0,5 , ou seja, considerando-se que em média $50 \%$ da biomassa é composta por carbono (Higuchi e Carvalho, 1994; Kraenzel et al., 2002; Soares e Oliveira, 2002), sobretudo porque o trabalho de Kraenzel et al. (2002) foi realizado com Teca e porque os trabalhos de Higuchi e Carvalho (1994) e de Soares e Oliveira (2002) dizem respeito a condições brasileiras.

Com as estimativas de carbono presentes nas folhas, nos galhos e no fuste das plantas-amostras, foram buscadas relações entre as quantidades de carbono total e volume de fuste, altura da copa para galhos e volume de copa para folhas.

Para fins de cálculo do volume da copa, admitiu-se a forma elipsoidal para copa das plantas de Teca, obtendo o volume pela equação:

$$
V=\frac{4 \pi}{3} \times\left(\frac{d 1}{2}\right) \times\left(\frac{d 2}{2}\right) \times\left(\frac{d 3}{2}\right)
$$

Em que:

$V=$ volume de copa $\left(\mathrm{m}^{3}\right)$;

$d 1$ = largura da projeção da copa na linha

(m);

$d 2=$ largura da projeção da copa na entrelinha $(\mathrm{m})$;

$d 3=$ diferença entre a altura do ápice e a altura da base da copa (m).

As medidas de projeção de copa foram realizadas nas linhas e nas entrelinhas das plantas. A altura do ápice e a altura da base da copa das plantas de Teca foram estimadas com auxílio de um clinômetro, obtendo-se os valores com a fórmula (Brauwers, 2004):

$$
H=h_{\text {olho }}+\operatorname{tg} \alpha \times D
$$

Em que:

$H=$ altura do ápice ou da base da copa das plantas de Teca (m);

$h_{\text {olho }}=$ altura do solo até o olho da pessoa que manuseia o clinômetro (m);

$\alpha=$ ângulo lido no aparelho $\left(^{\circ}\right)$;

$D=$ distância da pessoa que manuseia o clinômetro à planta que está sendo avaliada.

Nas mesmas três plantas amostradas para determinar a fitomassa da parte aérea, foi estimada a massa seca de raízes. Ela foi determinada por amostragem de solo com um trado (caneco) em quatro perfurações, sendo duas delas na linha a 0,55 $\mathrm{m}$ e $1,10 \mathrm{~m}$ e duas na entrelinha a $0,75 \mathrm{~m}$ e 1,50 $\mathrm{m}$ das plantas de Teca partindo do tronco, dividida em seis amostras de 0-0,15 m, 0,15-0,30 m, 0,30$0,45 \mathrm{~m}, 0,45-0,60 \mathrm{~m}, 0,60-0,75 \mathrm{~m}, 0,75-0,90 \mathrm{~m}$ de profundidade no solo e diâmetro de $0,10 \mathrm{~m}$. As coletas foram realizadas durante o período úmido em 25.10.2003, 25.02.2004 e 25.05.2004.

A separação do solo das raízes foi realizada por meio de lavagem em água corrente sobre um conjunto de peneiras de aço inox de malha de $1 \mathrm{~mm}$ e peneira de nylon de 120 mesh. Depois de limpas, as raízes foram acondicionadas em sacos de papel para secagem em estufa de circulação forçada a $70^{\circ} \mathrm{C}$ até atingirem peso constante determinando-se a massa seca.

A metodologia utilizada na quantificação da raiz pivotante foi a mesma adotada para $o$ fuste (parte cônica), ou seja, método de Smalian, admitindo o mesmo formato para a raiz pivotante. O solo foi escavado para a retirada da raiz pivotante, cujo comprimento total foi medido, e foi seccionada para extração de discos de aproximadamente $0,05 \mathrm{~m}$ de espessura, de $0,5 \mathrm{~m}$ em $0,5 \mathrm{~m}$ até o final.

A estimativa da quantidade de biomassa presente no conjunto de raízes da planta-amostra foi obtida multiplicando-se a densidade de raízes pelo volume de solo explorado pela planta. As respectivas estimativas de carbono consideraram o fator 0,48 , ou seja, considerando-se que em média $48 \%$ da biomassa das raízes são compostas por carbono, de acordo com o percentual encontrado para a espécie (Kraenzel et al., 2002).

Procedeu-se à quantificação da serapilheira acumulada por amostragem em coleta do material encontrado sobre a superfície do solo num espaço de $2,20 \mathrm{~m} \times 3,0 \mathrm{~m}$ entre quatro plantas. De cada talha, foram realizadas coletas nos meses de outubro de 2003, maio e setembro de 2004 com três repetições. Não foi realizada coleta no período mais chuvoso (março de 2004) por ser uma época submetida a intenso revolvimento no solo e baixo aporte de resíduo vegetal. O material coletado foi lavado e pesado, retirando-se uma subamostra que, em seguida, foi secada em estufa de circulação forçada de ar a $70^{\circ} \mathrm{C}$ até peso constante, sendo novamente pesada em balança de precisão $(0,01 \mathrm{~g})$. Após cada coleta, por considerar-se maior possibilidade de variação do teor de carbono, em função da decomposição da fitomassa, a subamostra da serapilheira acumulada foi levada ao laboratório para a determinação do teor de carbono, realizada 
conforme a metodologia de Tedesco et al. (1995) por meio de titulometria.

Para análise do teor de carbono do solo, foram recolhidas seis amostras, uma para cada faixa de profundidade de $0,15 \mathrm{~m}$ em $0,15 \mathrm{~m}$ até $0,90 \mathrm{~m}$ de profundidade, nos mesmos locais de amostragem das plantas, com três repetições por talhão de $3 \mathrm{em} 3$ meses, exceto o período seco da região. As amostras foram coletadas com um trado (caneca), e o volume de solo de cada perfil foi misturado, e em seguida retirou-se uma subamostra de aproximadamente $100 \mathrm{~g}$ de solo, embaladas, identificadas e levadas ao laboratório de análise de solo, para fins de medição do teor de carbono pela metodologia de Walkley-Black (EMBRAPA, 1997) utilizando-se a difenilamina como indicador externo.

$\mathrm{O}$ estoque de carbono no solo $\left(\mathrm{t} \mathrm{ha}^{-1}\right)$ foi calculado por meio da multiplicação do conteúdo de carbono (\%) dividido por cem, da densidade do solo $\left(\mathrm{g} \mathrm{cm}^{-3}\right)$, da espessura $(\mathrm{cm})$ da camada de solo e do fator de conversão de $\mathrm{g} \mathrm{cm}^{-2}$ para $\mathrm{t} \mathrm{ha}^{-1}(=100)$ (Szakács, 2003), de acordo com a fórmula:

$$
e=\frac{c}{100} \times d \times p \times 100\left(t h a^{-1}\right)=c \times d \times p t h a^{-1}
$$

Em que:

$$
\begin{aligned}
& e=\text { estoque de carbono; } \\
& c=\text { teor de carbono; } \\
& d=\text { densidade do solo; } \\
& p=\text { espessura da camada do solo. }
\end{aligned}
$$

A densidade aparente do solo foi determinada pelo método de anel volumétrico (EMBRAPA, 1997). As amostras foram coletadas de $0,15 \mathrm{~m}$ em $0,15 \mathrm{~m}$, concomitantes às de análises do teor de carbono no solo, em cada talhão.

$$
\text { densidade aparente }\left(\mathrm{gcm}^{-3}\right)=\frac{M}{V}
$$

Em que:

$$
\begin{aligned}
M & =\text { massa da amostra seca a } 105^{\circ} \mathrm{C} ; \\
V & =\text { volume da prova }
\end{aligned}
$$

A quantidade de carbono em cada idade ou estádio, no respectivo talhão com plantio de Teca, nos diversos compartimentos (acima e abaixo do solo), foi calculada considerando a densidade populacional de cada talhão. A contagem dos indivíduos procedeu-se por meio de três amostras $22 \times 30 \mathrm{~m}^{2}$ por hectare nas diferentes idades.

\section{RESULTADO E DISCUSSÃO}

O estoque total de carbono variou com a idade das plantas no talhão. Ao final do período de observação, no talhão com plantas na idade de 0,5 anos, ocorreu uma quantidade média de $122,5 \mathrm{t}$ de C ha ${ }^{-1}$; com 1,5 anos, 104,3 t de C ha ${ }^{-1}$; com 2,5 anos, 180,8 t de $\mathrm{C}^{-1}{ }^{-1}$; com 3,5 anos, 303,1 t de C ha' ${ }^{-1}$; e com 5,5 anos, 322,3 t de $\mathrm{C}$ ha ${ }^{-1}$. A redução entre a primeira e a segunda idade observadas provavelmente se deve a uma degradação do carbono do solo maior do que o acúmulo proporcionado pelo crescimento das plantas, considerando que a superfície do solo nesses estádios se encontra mais exposto diretamente aos efeitos da radiação solar e das chuvas.

$\mathrm{O}$ acúmulo médio esteve entre 2,3 $\mathrm{t}$ de $\mathrm{C}$ ha $^{-1}$ ano $^{-1}$ a 9,2 $\mathrm{tde} \mathrm{C} \mathrm{Ca}^{-1}$ ano $^{-1}$ (Figura 1). Houve um crescimento de $1,86 \%$ para o plantio com 0,5 ano, de $4,30 \%$ para o plantio com 1,5 ano, de $5,03 \%$ para o plantio com 2,5 anos, de $1,44 \%$ para o plantio com 3,5 anos e $2,16 \%$ para o plantio com 5,5 anos.

Kraenzel et al. (2002), no Panamá, fizeram uma avaliação pontual no tempo do estoque de carbono em Teca com 20 anos de idade, sem avaliação do acúmulo anual, e obtiveram $351 \mathrm{tde} C$ $\mathrm{ha}^{-1}$. As diferenças encontradas no presente trabalho, no que diz respeito ao estoque e ao acúmulo anual nas diferentes idades, indicam que o incremento anual não apresenta um padrão que dependa apenas da idade. Provavelmente, as condições ambientais ano a ano devem ser a principal causa de variação.

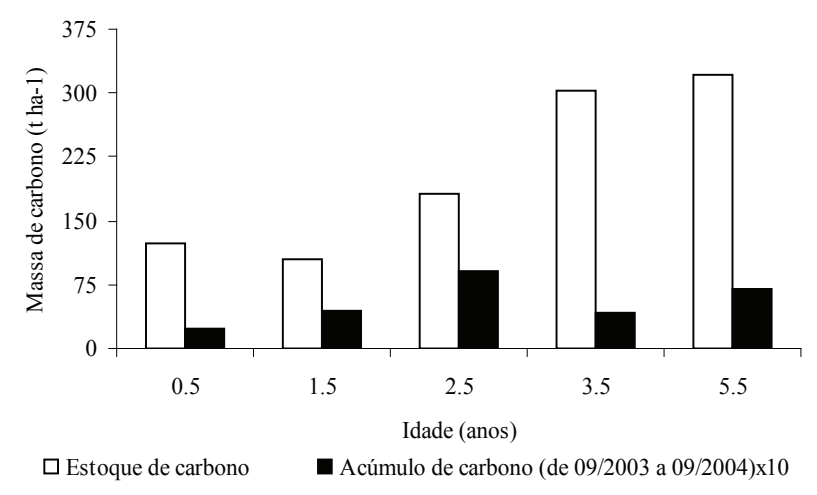

FIGURA 1: Estoque total de carbono em Teca (Tectona grandis L.f.) e acúmulo de carbono anual por hectare em diferentes idades.

FIGURE 1: Total carbon stock in teak (Tectona grandis L.f.) and annual increment by hectare at different ages. 
Almeida, E. M.; Campelo Júnior, J. H.; Finger, Z.

Considerando-se os valores absolutos do estoque de carbono em cada idade, apresentados na Figura 1, verifica-se que, até a idade de 5,5 anos (Tabela 1), do total de carbono do sistema com Teca, o maior percentual está no solo, independente da idade, perfazendo 90,8\% em média, seguido da parte aérea $5,04 \%$ das raízes $3,04 \%$ e serapilheira acumulada com $1,21 \%$. A quantidade de carbono e sua distribuição por componente na Teca variaram com a idade. Com o aumento da idade, houve uma redução no percentual de carbono para o solo, e uma tendência inversa para os percentuais de contribuição da parte aérea e das raízes para o sistema.

TABELA 1: Percentagens de estoque de carbono, por componente do sistema com plantio de Teca (Tectona grandis L.f.), em diferentes idades.

TABLE 1: Carbon stock percentage by component of teak (Tectona grandis L.f.) plantation system at different ages.

\begin{tabular}{ccccc}
\hline $\begin{array}{c}\text { Idade } \\
\text { inicial } \\
\text { (anos) }\end{array}$ & $\begin{array}{c}\text { Raízes } \\
(\%)\end{array}$ & $\begin{array}{c}\text { Serapilheira } \\
\text { acumulada }(\%)\end{array}$ & $\begin{array}{c}\text { Solo } \\
(\%)\end{array}$ & $\begin{array}{c}\text { Parte } \\
\text { aérea } \\
(\%)\end{array}$ \\
\hline 0,5 & 1,96 & 0,60 & 95,5 & 1,94 \\
1,5 & 2,59 & 0,61 & 93,0 & 3,80 \\
2,5 & 3,53 & 1,29 & 91,8 & 3,38 \\
3,5 & 2,46 & 0,85 & 90,3 & 6,39 \\
5,5 & 4,70 & 2,20 & 83,4 & 9,70 \\
\hline
\end{tabular}

Com relação à quantidade de carbono, somente na planta, verificou-se variação entre as diferentes idades, sendo que as plantas com 0,5 ano, 1,5 ano e 2,5 anos obtiveram em média $47,2 \%$ de carbono na raiz e $52,8 \%$ na parte aérea, e as plantas com 3,5 anos e 5,5 anos tiveram $31,4 \%$ de carbono na raiz e média de $68,6 \%$ na parte aérea.

Verificando a quantidade total de carbono nos talhões com Teca, com idades de 1,5; 2,5 e 3,5 anos, no início do experimento, e comparando essa quantidade com as medidas no final de um ano de observação, quando as plantas alcançaram respectivamente 2,$5 ; 3,5$; e 4,5 anos de idade, observou-se variação tanto na quantidade total de carbono, quanto em cada componente do sistema nas diferentes idades (Tabela 2), possivelmente influenciadas pela época da coleta. A primeira coleta coincidiu com o período seco da região, época em que a Teca apresentava-se praticamente sem folhas, com esse material depositado no solo.
TABELA 2: Média de carbono por componente do sistema com plantio de Teca (Tectona grandis L.f.), em diferentes idades, na primeira e quarta amostragem.

TABLE 2: Carbon mean by component of teak (Tectona grandis L.f.) plantation system at different ages at first and fourth sampling.

\begin{tabular}{|c|c|c|c|c|c|c|}
\hline \multirow[b]{3}{*}{ Idade (anos) } & \multicolumn{6}{|c|}{ Tonelada de carbono ha $^{-1}$} \\
\hline & \multicolumn{3}{|c|}{$\begin{array}{c}1^{\mathrm{a}} \text { coleta }- \\
11 / 09 / 2003\end{array}$} & \multicolumn{3}{|c|}{$\begin{array}{l}4^{\text {a }} \text { coleta }- \\
11 / 06 / 2004\end{array}$} \\
\hline & 1,5 & 2,5 & 3,5 & 1,5 & 2,5 & 3,5 \\
\hline Raiz & 3,6 & 6,7 & 4,9 & 3,4 & 8,6 & 11,3 \\
\hline Solo & 95 & 159 & 280 & 95 & 153 & 250 \\
\hline Parte aérea & 1,11 & 5,62 & 14,15 & 4,09 & 6,71 & 11,07 \\
\hline $\begin{array}{l}\text { Serapilheira } \\
\text { acumulada }\end{array}$ & 0,10 & 0,85 & 1,40 & 0,77 & 0,52 & 1,13 \\
\hline Total & 99,8 & 171,8 & 299,8 & 103,2 & 168,8 & 274,2 \\
\hline
\end{tabular}

\section{Estoque de carbono por componente}

Com relação às estimativas da quantidade de carbono da parte aérea (fuste, galhos e folhas) das plantas de Teça, observou-se que a maior contribuição média de carbono, independente da idade, encontrava-se no fuste com casca com $61 \%$, seguido das folhas com $27 \%$ e dos galhos com $12 \%$.

Soares e Oliveira (2002) encontraram proporções diferentes quanto à estimativa de carbono na parte aérea em povoamento de Eucalyptus grandis com 77 meses de idade, sendo as maiores concentrações no fuste $(83,24 \%)$, galhos $(6,87 \%)$ e folhas $(2,48 \%)$ em consequência, provavelmente, da característica da cultura.

Com base nos resultados apresentados na (Tabela 3), verificou-se que a Teca com 5,5 anos de idade estocou em média 31,24 t de $\mathrm{C}$ por hectare na parte aérea. $\mathrm{O}$ maior crescimento foi observado entre as idades de 2,5 e 3,5 anos. A partir daí, é possível que se verifique um crescimento linear com o tempo, se for levado em conta que Kraenzel et al. (2002) encontraram no Panamá, em quatro povoamentos de Teca com 20 anos de idade, média de $104,5 \mathrm{t}$ de $\mathrm{C}$ por hectare na parte aérea.

A quantidade de carbono no fuste variou conforme o aumento da idade (Tabela 3) e com o aumento do volume do fuste (Figura 2), demonstrando tendência crescente para as diferentes idades e ao longo do ano.

Em média, o acúmulo de carbono no fuste 
TABELA 3: Quantidade absoluta e relativa de carbono por componente na parte aérea das plantas de Teca (Tectona grandis L.f.).

TABLE 3: Absolute and relative carbon amounts by component in the aerial part of teak (Tectona grandis L.).

\begin{tabular}{|c|c|c|c|c|c|c|c|}
\hline \multicolumn{8}{|c|}{ Carbono na parte aérea } \\
\hline \multirow{2}{*}{$\begin{array}{l}\text { Idade inicial } \\
\quad \text { (anos) }\end{array}$} & \multicolumn{2}{|c|}{ Fuste } & \multicolumn{2}{|c|}{ Galhos } & \multicolumn{2}{|c|}{ Folhas } & \multirow{2}{*}{$\begin{array}{c}\text { Média } \\
\text { t de } \mathrm{C} \text { ha }^{-1}\end{array}$} \\
\hline & $\mathrm{tde} C$ ha $^{-1}$ & $(\%)$ & $\mathrm{tde} C \mathrm{ha}^{-1}$ & (\%) & $\mathrm{t} \mathrm{de} \mathrm{C} \mathrm{ha-1}$ & $(\%)$ & \\
\hline 0,5 & 1,07 & $(45,5)$ & 0,13 & $(5,5)$ & 1,16 & $(49,4)$ & 2,35 \\
\hline 1,5 & 2,75 & $(69,4)$ & 0,29 & $(7,3)$ & 0,92 & $(23,5)$ & 3,96 \\
\hline 2,5 & 4,27 & $(63,1)$ & 0,35 & $(29,0)$ & 2,15 & $(31,7)$ & 6,77 \\
\hline 3,5 & 13,41 & $(69,8)$ & 1,69 & $(8,8)$ & 4,13 & $(21,4)$ & 19,22 \\
\hline 5,5 & 22,15 & $(70,9)$ & 4,64 & $(14,8)$ & 4,46 & $(14,3)$ & 31,24 \\
\hline
\end{tabular}

foi de $1,05 \mathrm{t} \mathrm{de} \mathrm{C}$ ha $^{-1} \mathrm{ano}^{-1}$ para as plantas com 0,5 anos, $1,95 \mathrm{t} \mathrm{de} \mathrm{C} \mathrm{ha-1}$ ano $^{-1}$ para as plantas com 1,5 anos, $0,98 \mathrm{t} \mathrm{de} \mathrm{C} \mathrm{ha}^{-1}$ ano $^{-1}$ para as plantas com 2,5 anos, 5,47 te C ha ${ }^{-1}$ ano $^{-1}$ para as plantas com 3,5 anos e 5,51 t de C ha- ano $^{-1}$ para as plantas com 5,5 anos. Utilizando os resultados de Kraenzel et al. (2002), verifica-se que, com 20 anos, o acúmulo de carbono se mantém aproximadamente na mesma proporção de 5,10 t de $\mathrm{C} \mathrm{ha}^{-1} \mathrm{ano}^{-1}$, em média.

É importante ressaltar que proporcionalmente sobressaíram-se as plantas com 0,5 anos, com aumento de carbono 68,3 vezes o valor inicial, durante o ano de observação. Como as plantas ainda eram relativamente jovens, provavelmente ainda não havia competição entre elas por água e luz, levando qualquer aumento de área foliar a provocar taxas de crescimento cada vez maiores, que corresponde à fase exponencial do padrão sigmóide de crescimento biológico.

A quantidade média de carbono estimada nos galhos de Teca, no período de 11.09.2003 a 11.06.2004 (Tabela 3) apresentou maior crescimento para as plantas com 2,5 anos, com taxa de $29 \%$ e um menor crescimento para as plantas com 0,5 anos, com taxa de 5,53\%.Tal fato pode ser explicado pela variação em altura de copa (Figura 2). Outro fato, a se destacar quanto ao comportamento do carbono nos galhos, foi que o aparecimento de galhos em todos os plantios se deu a partir de 1,5 anos de idade.

As quantidades médias de carbono observadas nas folhas (Tabela 3) variaram de 0,92 $\mathrm{t}$ de $\mathrm{C} \mathrm{ha}^{-1}$ para as plantas com 1,5 anos, a 4,46 t de $\mathrm{C} \mathrm{ha}^{-1}$ para as plantas com 5,5 anos, sendo que, em média, as plantas com 2,5 anos apresentaram o maior percentual, com $31,75 \%$.

A quantidade de carbono nas folhas, nas diferentes idades e ao longo do ano, foi verificada considerando como parâmetro de quantificação os valores de volume de copa (Figura 2).
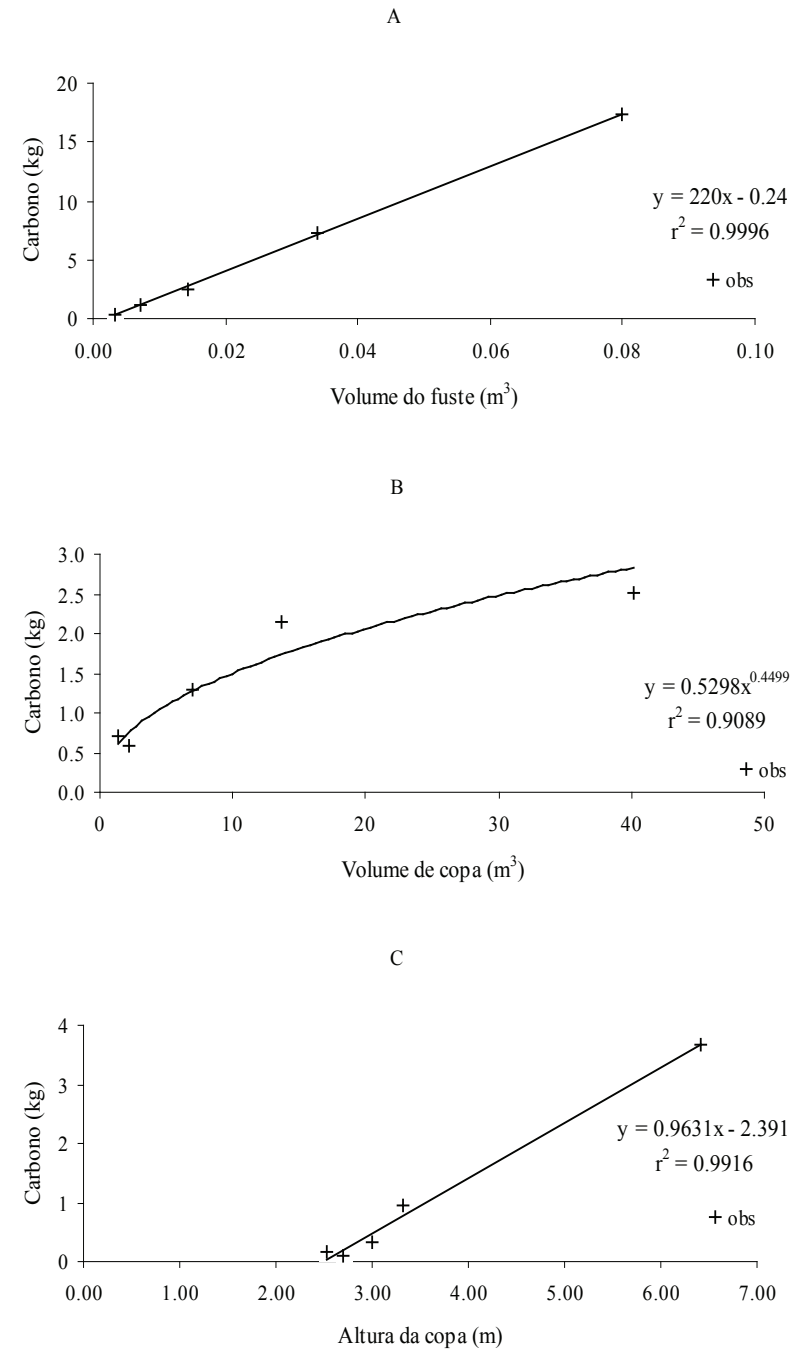

FIGURA 2: Quantidades de carbono nos fustes (A), nas folhas (B) e nos galhos (C), em função do volume de fuste, volume de copa e altura da copa respectivamente.

FIGURE 2: Carbon amounts in the trunk (A), in the leaves (B) and in the stems (C), by trunk volume, canopy volume and canopy height, respectively. 
A quantidade de carbono na parte aérea das plantas de Teca variou com a idade. Pode-se observar que o aumento de carbono foi proporcional ao aumento da idade com tendência progressivamente crescente para os fustes, galhos e folhas em todos os talhões, exceto para as folhas no talhão com 1,5 anos.

Como se pode observar na Figura 2, os dados coletados no presente trabalho permitiram encontrar relações alométricas que possibilitam estimar a quantidade de carbono partindo de medidas indiretas como as variáveis volume de fuste, volume de copa e altura da copa.

Nas avaliações da quantidade de carbono nas raízes (Figura 3), verificou-se uma tendência proporcionalmente crescente, entre aumento da idade e quantidade de carbono, sendo em média 2,8 t de $\mathrm{C} \mathrm{ha} \mathrm{h}^{-1}$ para as plantas mais jovens e de 15,3 t de $\mathrm{C}$ ha $^{-1}$ para as plantas mais velhas. Kraenzel et al. (2002) no Panamá, com Teca de 20 anos de idade, obtiveram 15,7 $\mathrm{t}$ de $\mathrm{C}$ ha ${ }^{-1}$ nas raízes, um resultado semelhante ao deste trabalho, indicando que não deve ocorrer um crescimento significativo do sistema radicular da planta depois da idade de 5,5 anos.

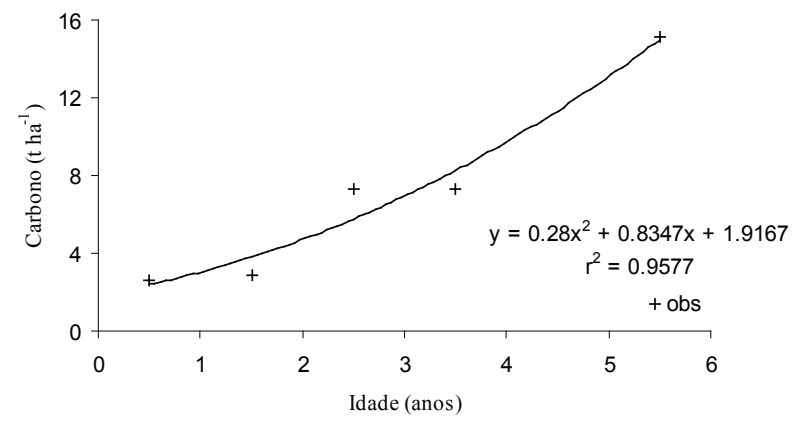

FIGURA 3: Quantidade de carbono nas raízes de Teca (Tectona grandis L.f.), em diferentes idades.

FIGURE 3: Carbon amounts of teak (Tectona grandis L.f.) in roots, at different ages.

De modo geral, observou-se que, com o aumento da profundidade no solo, houve redução proporcional em massa de raízes e quantidade de carbono em todas as idades amostradas. Essa redução foi mais acentuada para as plantas com 0,5 anos de idade e, menos acentuada para as plantas com 5,5 anos de idade. Considerando a proporcionalidade de biomassa de raízes e quantidade de carbono, nota-se que os resultados desse trabalho confirmam dados da literatura que, segundo Andrae e Krapfenbauer
(1983), as maiores densidades de raízes estão nas primeiras camadas de solo e, consequentemente, as maiores quantidades de carbono.

As maiores quantidades médias de carbono do solo estavam nos talhões com idade de 3,5 e 5,5 anos com $274 \mathrm{t}$ de $\mathrm{C}$ ha ${ }^{-1}$ e $269 \mathrm{t} \mathrm{de} \mathrm{C} \mathrm{ha}^{-1}$ respectivamente (Tabela 4). Resultado diferente foi encontrado por Kraenzel et al. (2002) em plantações de Teca no Panamá com $225 \mathrm{t}$ de $\mathrm{C}$ ha ${ }^{-1}$ numa profundidade de $2 \mathrm{~m}$ e densidade de solo entre 0,63 e $0,75 \mathrm{~g} \mathrm{~cm}^{-3}$. As densidades observadas na Tabela 4 indicam que a aeração do solo nas condições do presente trabalho foram mais desfavoráveis à decomposição aeróbica da matéria orgânica do solo.

Corazza et al. (1999) nos campos experimentais da Embrapa de Planaltina e Distrito Federal, encontraram também resultados diferentes entre região de cerrado com 133,6 t de $\mathrm{C} \mathrm{ha}^{-1} \mathrm{e}$ em reflorestamento de eucalipto 148,2 t de $\mathrm{C} \mathrm{ha}^{-1}$ com densidade de solo $0,81 \mathrm{~g} \mathrm{~cm}^{-3}$ e $0,90 \mathrm{~g} \mathrm{~cm}^{-3}$ respectivamente e profundidade de um metro. Esses resultados demonstraram que a profundidade e a densidade do solo influenciaram na quantificação do carbono.

A diferença no estoque de carbono do solo, nas diferentes idades, pode estar relacionada com o procedimento de manejo (sistema de preparo com intenso revolvimento), adotado nas parcelas com plantio de Teca nos primeiros anos, para evitar competições com ervas daninhas e gramíneas, prejudicando o conteúdo de matéria orgânica. Tais fatores refletiram na quantidade de carbono armazenado no solo observado neste trabalho em que praticamente não houve acúmulo de carbono no solo, exceto para os talhões com 3,5 anos e 5,5 anos

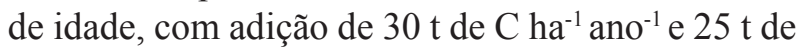
$\mathrm{C} \mathrm{ha}^{-1}$ ano $^{-1}$ respectivamente.

Corazza et al. (1999) encontraram resultados diferentes quanto à adição de carbono em plantio direto com 15 anos de cultivo, com taxa acumulativa de $1,43 \mathrm{t} \mathrm{de} \mathrm{C} \mathrm{ha}{ }^{-1}$ ano $^{-1}$ na região de cerrado. Bayer et al. (2003), avaliando o efeito da introdução de leguminosas em sistemas de produção de milho, em consórcio, em Chapecó, SC, encontraram taxas de acúmulo variando entre 0,39 a $2,23 \mathrm{t}$ de $\mathrm{C} \mathrm{ha}^{-1}$ ano $^{-1}$. A adição do carbono no solo depende também do grau de intensidade de perturbação do solo, da quantidade de resíduos retornados ao solo e das condições edafoclimáticas.

A quantidade de carbono na serapilheira acumulada variou em média de 0 a $0,77 \mathrm{t}$ de $\mathrm{C}$, de 0,10 a 0,52 t de $\mathrm{C}$, de 0,85 a 1,13 t de $\mathrm{C}$, de 1,40 
TABELA 4: Quantidade de carbono no solo e da densidade do solo em plantações de Teca (Tectona grandis L.f.) nas diferentes idades ao longo do ano.

TABLE 4: Soil carbon amounts and soil density in teak (Tectona grandis L.f.) plantations, at different ages.

\begin{tabular}{cccccccc}
\hline \multicolumn{7}{c}{ Carbono no solo } \\
\multirow{2}{*}{$\begin{array}{c}\text { Idade inicial } \\
\text { (anos) }\end{array}$} & $\begin{array}{c}25 / 10 / 2003 \\
\text { t de C } \\
\text { ha }^{-1}\end{array}$ & $\begin{array}{c}\text { Dens. } \\
\mathrm{g} \mathrm{cm}^{-3}\end{array}$ & $\begin{array}{c}\mathrm{t} \mathrm{de} \mathrm{C} \\
\mathrm{ha}^{-1}\end{array}$ & $\begin{array}{c}\text { Dens. } \\
\mathrm{g} \mathrm{cm}^{-3}\end{array}$ & $\begin{array}{c}\mathrm{t} \mathrm{de} \mathrm{C} \\
\mathrm{ha}^{-1}\end{array}$ & $\begin{array}{c}\text { Dens. } \\
\mathrm{g} \mathrm{cm}^{-3}\end{array}$ & $\begin{array}{c}\mathrm{t} \mathrm{de} \mathrm{C} \\
\mathrm{ha}^{-1}\end{array}$ \\
\hline 0,5 & 126 & 1,20 & 113 & 1,11 & 112 & 1,28 & 117 \\
1,5 & 95 & 1,08 & 101 & 1,20 & 95 & 1,25 & 97 \\
2,5 & 159 & 1,16 & 165 & 1,22 & 153 & 1,29 & 165 \\
3,5 & 250 & 1,20 & 293 & 1,22 & 280 & 1,40 & 274 \\
5,5 & 256 & 1,09 & 270 & 1,05 & 281 & 1,29 & 269 \\
\hline
\end{tabular}

TABELA 5: Quantidade absoluta e relativa de carbono na serapilheira acumulada em plantações de Teca (Tectona grandis L.f.).

TABLE 5: Absolute and relative carbon amounts in the litter of teak (Tectona grandis L.f.) plantations.

\begin{tabular}{cccccccc}
\hline \multicolumn{7}{c}{ Serapilheira acumulada } \\
\hline \multirow{2}{*}{$\begin{array}{c}\text { Idade inicial } \\
\text { (anos) }\end{array}$} & \multicolumn{2}{c}{$11 / 12 / 2003$} & \multicolumn{2}{c}{$11 / 06 / 2004$} & \multicolumn{2}{c}{$09 / 09 / 2004$} & Média \\
\cline { 2 - 9 } & $\begin{array}{c}\text { Teor de C } \\
(\%)\end{array}$ & $\begin{array}{c}\mathrm{t} \mathrm{de} \mathrm{C} \\
\mathrm{ha}^{-1}\end{array}$ & $\begin{array}{c}\text { Teor de C } \\
(\%)\end{array}$ & $\begin{array}{c}\mathrm{tde} \mathrm{C} \\
\mathrm{ha}^{-1}\end{array}$ & $\begin{array}{c}\text { Teor de C } \\
(\%)\end{array}$ & $\begin{array}{c}\mathrm{tde} \mathrm{C} \\
\mathrm{ha}^{-1}\end{array}$ & $\begin{array}{c}\mathrm{t} \mathrm{de} \mathrm{C} \\
\mathrm{ha}^{-1}\end{array}$ \\
\hline 0,5 & - & - & 42,15 & 0,12 & 43,5 & 0,77 & 0,30 \\
1,5 & 32,7 & 0,10 & 40,20 & 0,11 & 44,7 & 0,52 & 0,24 \\
2,5 & 42,08 & 0,85 & 40,05 & 0,95 & 41,4 & 1,13 & 0,99 \\
3,5 & 42,38 & 1,40 & 40,80 & 0,85 & 41,7 & 0,87 & 1,04 \\
5,5 & 42,71 & 3,68 & 40,65 & 1,93 & 43,5 & 2,42 & 2,68 \\
\hline
\end{tabular}

a $0,87 \mathrm{t}$ de $\mathrm{C}$, de 3,68 a $1,93 \mathrm{t}$ de $\mathrm{C}$ por hectare, respectivamente, para os talhões com $0,5,1,5,2,5$, 3,5 e 5,5 anos de idade (Tabela 5). As oscilações na quantidade de carbono podem ser atribuídas à deposição de serapilheira que está relacionada com a queda dos ramos e folhas Schumacher et al. (2003), época de amostragem e com o grau de decomposição da biomassa.

Kraenzel et al. (2002), trabalhando com Teca de 20 anos, obtiveram $3,4 \mathrm{t} \mathrm{de} \mathrm{C} \mathrm{ha}^{-1}$, resultado que difere do presente trabalho com $2,7 \mathrm{tde} \mathrm{Cha}^{-1} \mathrm{em}$ Teca com 5,5 anos. Tal fato se deve ao aumento em volume de copa com a idade e, consequentemente, uma maior produção de massa de serapilheira acumulada e carbono.

\section{CONCLUSÕES}

O estoque de carbono em talhões cultivados com Teca de até 5,5 anos de idade varia de forma crescente com a idade, entre aproximadamente 100 e $300 \mathrm{t}$ de $\mathrm{C} \mathrm{ha}^{-1}$, e a maior proporção está no solo.

$\mathrm{O}$ estoque de carbono no solo apresenta uma redução inicial no primeiro ano, mas cresce com a idade nos anos seguintes.

Em talhões comerciais de cultivo de Teca, as quantidades de carbono nos fustes, nas folhas e nos galhos de Teca podem ser estimadas satisfatoriamente em função do volume de fuste, volume de copa e altura da copa respectivamente.

\section{REFERÊNCIAS BIBLIOGRÁFICAS}

ANDRAE, F.; KRAPFENBAUER, A. Distribuição de raízes finas do pinheiro bravo (Podocarpos lambertii) e do pinheiro brasileiro (Araucaria angustifolia). In: PESQUISAS AUSTRO BRASILEIRAS (1973-1982). Santa Maria: UFSM, 1983. p. 56-67.

BAYER, C. et al. Incremento de carbono e nitrogênio num latossolo pelo uso de plantas estivais para cobertura do solo. Ciência Rural, Santa Maria, v. 33, n. 3, p. 469-475, 2003.

BRAUWERS, L. R. Interceptação da radiação solar, crescimento e produção dos componentes de sistema agroflorestal. 2004. 58 f. Dissertação 
(Mestrado em Agricultura Tropical)-Faculdade de Agronomia e Medicina Veterinária, Universidade Federal de Mato Grosso, Cuiabá, 2004.

CORAZZA, E. J. et al. Comportamento de diferentes sistemas de manejo como fonte ou depósito de carbono em relação à vegetação de cerrado. Revista Brasileira de Ciência do Solo, Viçosa, v. 23, n. 2, p. 425-432, 1999.

EMBRAPA. Empresa Brasileira de Pesquisa agropecuária. Centro Nacional de Pesquisas do Solo. Manual de métodos de análise de solo. 2 .ed. Rio de Janeiro: 1997. 212 p.

EMBRAPA. Empresa Brasileira de Pesquisa agropecuária. Centro Nacional de Pesquisas do Solo. Sistema brasileiro de classificação de solos. Rio de Janeiro: 1999.

FINGER, Z; FINGER, F. A.; DRESCHER, R. Teca (Tectona grandis L.f.): plante esta idéia. In: SIMPÓSIO BRASILEIRO DE PÓSGRADUAÇÃO EM ENGENHARIAFLORESTAL, 1., 2001, Santa Maria. Anais... Santa Maria: UFSM, 2001. 1 CD-Rom.

HERRERA, M. C. F. Densidade Básica e equações de peso de madeira seca de povoamentos de eucalipto de acordo com a idade, espécie e método de regeneração. 1989. 113 f. Dissertação (Mestrado em Ciência Florestal)-Universidade Federal de Viçosa, Viçosa, 1989.

HIGUCHI, N.; CARVALHO, J. A. Fitomassa e conteúdo de carbono de espécies arbóreas da Amazônia. In: SEMINÁRIO "EMISSÕES X SEQÜESTRO DE $\mathrm{CO}_{2}$ - Uma nova oportunidade de negócios para o Brasil". 1994, Rio de Janeiro.
Anais... Rio de Janeiro: CVRD-Companhia Vale do Rio Doce, 1994. p.127-153, 1994.

KRAENZEL, M. et al. Carbon storage of harvest age teka (Tectona grandis L.f.) plantations, Panama. Forest Ecology and Management, n.5863, p. 1-13, 2002.

OLIVEIRA, L. C. Teca: alternativa de produção florestal na Amazônia. Rio Branco: Embrapa Acre, 2004. Disponível em: www.embrapaacre.gov.br. Acesso em 17 out 2004.

SCHUMACHER, M. V. et al. Retorno de nutrientes via deposição de serapilheira em um povoamento de acácia-negra (Acacia mearnsii De Wild.) no Estado do Rio Grande do Sul. Revista Árvore, Viçosa, v. 27, n. 6, p. 791-798, 2003.

SOARES, C. P. B.; OLIVEIRA, M. L. R. Equações para estimar a quantidade de carbono na parte aérea de árvores de eucalipto em Viçosa, Minas Gerais. Revista Árvore, Viçosa, v. 26, n. 5, p. 534-539, 2002.

SZAKÁCS, G. G. J. Seqüestro de carbono nos solos - Avaliação das potencialidades dos solos arenosos sob pastagens, Anhembi-Piracicaba SP. 2003.128 f. Dissertação (Mestrado em Ciências Agrárias, área de concentração energia nuclear na agricultura)-CENA, Universidade de São Paulo, Piracicaba, 2003.

TEDESCO, M. J. et al. Análise de solo, plantas e outros materiais. Porto Alegre: UFRGS, 1995. 118 p. (Boletim Técnico, 5).

VITAL, B. R. Métodos de determinação da densidade da madeira. Viçosa: SIF, 1984. 21 p.

(Boletim Técnico, 2). 